\title{
Coherency effects on the mixing thermodynamics of cubic Ti1-xAlxN/TiN(001) multilayers
}

Fei Wang, Igor Abrikosov, Sergey Simak, Magnus Odén, Frank Muecklich and Ferenc

Tasnadi

\section{Linköping University Post Print}

N.B.: When citing this work, cite the original article.

Original Publication:

Fei Wang, Igor Abrikosov, Sergey Simak, Magnus Odén, Frank Muecklich and Ferenc Tasnadi, Coherency effects on the mixing thermodynamics of cubic Ti1-xAlxN/TiN(001) multilayers, 2016, PHYSICAL REVIEW B, (93), 17, 174201.

http://dx.doi.org/10.1103/PhysRevB.93.174201

Copyright: American Physical Society

http://www.aps.org/

Postprint available at: Linköping University Electronic Press

http://urn.kb.se/resolve?urn=urn:nbn:se:liu:diva-129166 


\title{
Coherency effects on the mixing thermodynamics of cubic $\operatorname{Ti}_{1-x} \mathrm{Al}_{x} \mathrm{~N} / \mathrm{TiN}(001)$ multilayers
}

\author{
Fei Wang, ${ }^{1,2, *}$ Igor A. Abrikosov, ${ }^{1,3,4}$ Sergei I. Simak, ${ }^{1}$ Magnus Odén, ${ }^{1}$ Frank Mücklich, ${ }^{2}$ and Ferenc Tasnádi ${ }^{1}$ \\ ${ }^{1}$ Department of Physics, Chemistry and Biology (IFM), Linköping University, SE-581 83 Linköping, Sweden \\ ${ }^{2}$ Functional Materials, Materials Science and Engineering Department (MSE), Saarland University, P.O. Box 151150, \\ 66041 Saarbrücken, Germany \\ ${ }^{3}$ Materials Modeling and Development Laboratory, NUST “MISIS,” 119049 Moscow, Russia \\ ${ }^{4}$ LACOMAS Laboratory, Tomsk State University, 634050 Tomsk, Russia \\ (Received 7 January 2016; revised manuscript received 1 April 2016; published 9 May 2016)
}

\begin{abstract}
In this work, we discuss the mixing thermodynamics of cubic (B1) $\mathrm{Ti}_{1-x} \mathrm{Al}_{x} \mathrm{~N} / \mathrm{TiN}(001)$ multilayers. We show that interfacial effects suppress the mixing enthalpy compared to bulk $\operatorname{Ti}_{1-x} \mathrm{Al}_{x} \mathrm{~N}$. The strongest stabilization occurs for compositions in which the mixing enthalpy of bulk $\mathrm{Ti}_{1-x} \mathrm{Al}_{x} \mathrm{~N}$ has its maximum. The effect is split into a strain and an interfacial (or chemical) contribution, and we show that both contributions are significant. An analysis of the local atomic structure reveals that the Ti atoms located in the interfacial layers relax significantly different from those in the other atomic layers of the multilayer. Considering the electronic structure of the studied system, we demonstrate that the lower Ti-site projected density of states at $\epsilon_{\mathrm{F}}$ in the $\mathrm{Ti}_{1-x} \mathrm{Al}_{x} \mathrm{~N} / \mathrm{TiN}$ multilayers compared to the corresponding monolithic bulk explains a decreased tendency toward decomposition.
\end{abstract}

DOI: 10.1103/PhysRevB.93.174201

\section{INTRODUCTION}

Superhard materials have been synthesized in the form of superlattices, such as TiN/V(Nb)N [1-3] and ZrN/CN [4], or as nanocomposites, $\mathrm{ZrN}-\mathrm{SiN}$ [5], etc. Three major effects-the lattice strain (coherency) and elastic mismatch [6] and the interfacial chemistry - are generally attributed to the observed interfacial strengthening [7]. It has been shown that in multilayers with coherent interfaces, the relevant one is the coherency strain effect [8]. However, one should stress that decoupling the strain or lattice mismatch effects from the chemical ones is not straightforward.

Ozoliņš et al. [9] have developed a theoretical approach to discuss the $a b$ initio thermodynamics of immiscible superlattices. In this technique, one splits the superlattice formation energy into a constituent strain and interfacial or chemical contribution, which allows for a separation of the strain effects from the chemical ones. Crystallographic investigations (diffraction-based techniques such as XRD, TEM, etc.) of multilayers access lattice parameters and interlayer distances that are affected by the interfacial chemistry. Therefore, the extracted coherency strain is not equal to the derived theoretical constituent strain.

In $\mathrm{Ti}_{1-x} \mathrm{Al}_{x} \mathrm{~N} / \mathrm{TiN}(001)$ multilayers, extended age hardening is observed $[10,11]$ by the spinodal decomposition of $\mathrm{Ti}_{1-x} \mathrm{Al}_{x} \mathrm{~N}$ [12]. Understanding the role of lattice coherency and interfacial chemistry on the driving force of this decomposition process is unexplored. However, modeling multilayers built from alloys is a theoretical challenge [13]. Van de Walle used the cluster expansion technique to predict the compositional profile in Samarium-doped coherent Ceria superlattices [14], and convergence was achieved with the inclusion of 70000 atoms. Advanced theoretical investigations based on the special quasirandom structure (SQS) approach [15] have exposed the electronic origin of the thermodynamic instability in $\mathrm{Ti}_{1-x} \mathrm{Al}_{x} \mathrm{~N}$ alloys [12]. Recent

\footnotetext{
*feiwa@ifm.liu.se
}

molecular-dynamics simulations confirm the high positive value of the mixing free energy in $\mathrm{Ti}_{1-x} \mathrm{Al}_{x} \mathrm{~N}$ alloys at elevated temperature [16].

In this work, we investigate the effect of lattice coherency on the mixing thermodynamics in cubic (B1) $\mathrm{Ti}_{1-x} \mathrm{Al}_{x} \mathrm{~N} / \mathrm{TiN}(001)$ multilayers. We extend the method by Ozoliņš et al. [9] to multilayers with alloys, and we introduce a decomposition of the observed effect into strain and chemical (interfacial) contributions. We base our description on the concept of coherency strain rather than the constituent one because it allows us to connect the results of the simulations to an experimental interpretation. We propose that both strain and interface chemistry contribution are important, and we show that the chemical effect gives rise to a displacement from the ideal positions of the $\mathrm{Ti}$ atoms on both sides of the interface. By calculating the Ti-site partial density of states, we reveal the electronic contribution to the stabilization of $\mathrm{Ti}_{1-x} \mathrm{Al}_{x} \mathrm{~N} / \mathrm{TiN}(001)$ multilayers.

\section{CAlCulational Details}

The multilayer (ML) structures were generated by sandwiching $\ell_{1}$ monolayers of $\mathrm{B} 1 \mathrm{Ti}_{1-x} \mathrm{Al}_{x} \mathrm{~N}$ between $\ell_{2}$ monolayers of B1 TiN periodically along the [001] orientation. The two cubic slabs form a coherent interface. The in-plane size of the models was $(3 \times 3)$ based on the B1 conventional cell. We generated multilayers with two different periodicities, i.e., $\ell_{1} / \ell_{2}$ was either $6 / 6$ or $12 / 6$. The alloys were modeled within the special quasirandom structure approach [15] with an $\mathrm{Al}$ mole fraction $(x)$ grid starting from 0 up to 1 using steps of $1 / 9$. The atomic configurations in the $\mathrm{Ti}_{1-x} \mathrm{Al}_{x} \mathrm{~N}$ supercells were obtained by minimizing the Warren-Cowley pair short-rangeorder (SRO) $[17,18]$ parameters up to the seventh nearestneighboring shells in the metal sublattice while demanding the same Al concentration in each monolayer [13]. This provides an alignment of the ML models for different $x$. The assumption of a sharp compositional interfacial region is valid if the interface thickness is negligible with respect to the slab thicknesses of both $\mathrm{Ti}_{1-x} \mathrm{Al}_{x} \mathrm{~N}$ and TiN. Furthermore, 
Chu and Barnett [19] have investigated superlattices with finite interface width using a phenomenological model that provided quantitative agreements with experiments for nitride superlattices. They predicted larger interfacial strengthening for sharper interfaces.

The mixing enthalpy in the $\mathrm{Ti}_{1-x} \mathrm{Al}_{x} \mathrm{~N} / \mathrm{TiN}(001)$ multilayer is calculated by the energy difference

$$
\begin{aligned}
& \Delta H^{\mathrm{Ti}_{1-x} \mathrm{Al} \mathrm{l}_{x} \mathrm{~N} / T i N}\left(x, \ell_{1}, \ell_{2}\right) \\
& \quad=\frac{1}{N}\left(E_{\ell_{1} / \ell_{2}}^{\mathrm{Ti}_{1-x} \mathrm{Al}_{x} \mathrm{~N} / \mathrm{TiN}}(x)-(1-x) E_{\ell_{1} / \ell_{2}}^{\mathrm{TiN}}-x E_{\ell_{1} / \ell_{2}}^{\mathrm{AlN} / \mathrm{TiN}}\right),
\end{aligned}
$$

where $N$ is the total number of atoms in the $\mathrm{Ti}_{1-x} \mathrm{Al}_{x} \mathrm{~N}$ slab; $E_{\ell}^{A}$ denotes the total energy of material $A$ with $\ell$ layers along (001), which is taken for the calculated equilibrium volume for each specific system and composition.

The total energy calculations were performed within density functional theory (DFT) using the projector augmented wave (PAW) [20] approach implemented in the Vienna $\mathrm{Ab}$ initio Simulation Package (VASP) [21-23]. The exchangecorrelation energy was approximated by the PerdewBurke-Ernzerhof generalized gradient functional (PBE-GGA) $[24,25]$. In the calculations, we applied a plane-wave cutoff energy of $400 \mathrm{eV}$, and reciprocal-space integration was performed within the Monkhorst-Pack scheme [26] using $k$-meshes of $(4 \times 4 \times 2)$ for $\ell_{1} / \ell_{2}=6 / 6$ and $(3 \times 3 \times 1)$ in the case of $\ell_{1} / \ell_{2}=12 / 6$. These parameters result in $\approx 1 \mathrm{meV} / \mathrm{at}$ accuracy in the mixing enthalpy. The structural parameters of the SQS supercells were relaxed while keeping the tetragonal cell shape. The total and projected densityof-states calculations were done on the relaxed structures using a higher $k$-mesh: $(6 \times 6 \times 3)$ for the $6 / 6$ multilayer and $(6 \times 6 \times 6)$ for bulk. The energy cutoff was then changed to $520 \mathrm{eV}$.

\section{RESULTS AND DISCUSSION}

Figure 1 shows the calculated mixing enthalpies of $\mathrm{Ti}_{1-x} \mathrm{Al}_{x} \mathrm{~N}$ in multilayers (MLs) compared with its monolithic (bulk) form. The bulk values match well with other literature [12]. All the mixing enthalpy values are positive, indicating a thermodynamic driving force toward phase separation. The ML mixing enthalpies are significantly suppressed with respect to the bulk values, which means that in the multilayer structure the coherent TiN confinement has a stabilization effect on the $\mathrm{Ti}_{1-x} \mathrm{Al}_{x} \mathrm{~N}$ slab. It confirms the differential scanning calorimetry observation that $\mathrm{Ti}_{1-x} \mathrm{Al}_{x} \mathrm{~N}$ slabs in multilayers have an improved thermal stability [10]. The stabilization effect is smaller in the thicker $12 / 6 \mathrm{ML}$ as the overall system is more similar to the bulk alloy. However, this decrease is not just an arithmetic consequence of having twice as many atoms in the 12/6 ML; see the dashed lines in Fig. 1.

Furthermore, the ML curves maxima show the same asymmetric shift to higher compositions as in the bulk. Comparing the $6 / 6$ and $12 / 6$ MLs, one sees that this tilting toward higher compositions is lower in the $12 / 6$ case, which suggests a compositionally increasing term that is gradually decreasing with increased periodicity. A quantity that behaves in this way is the in-plane lattice mismatch (strain) shown in
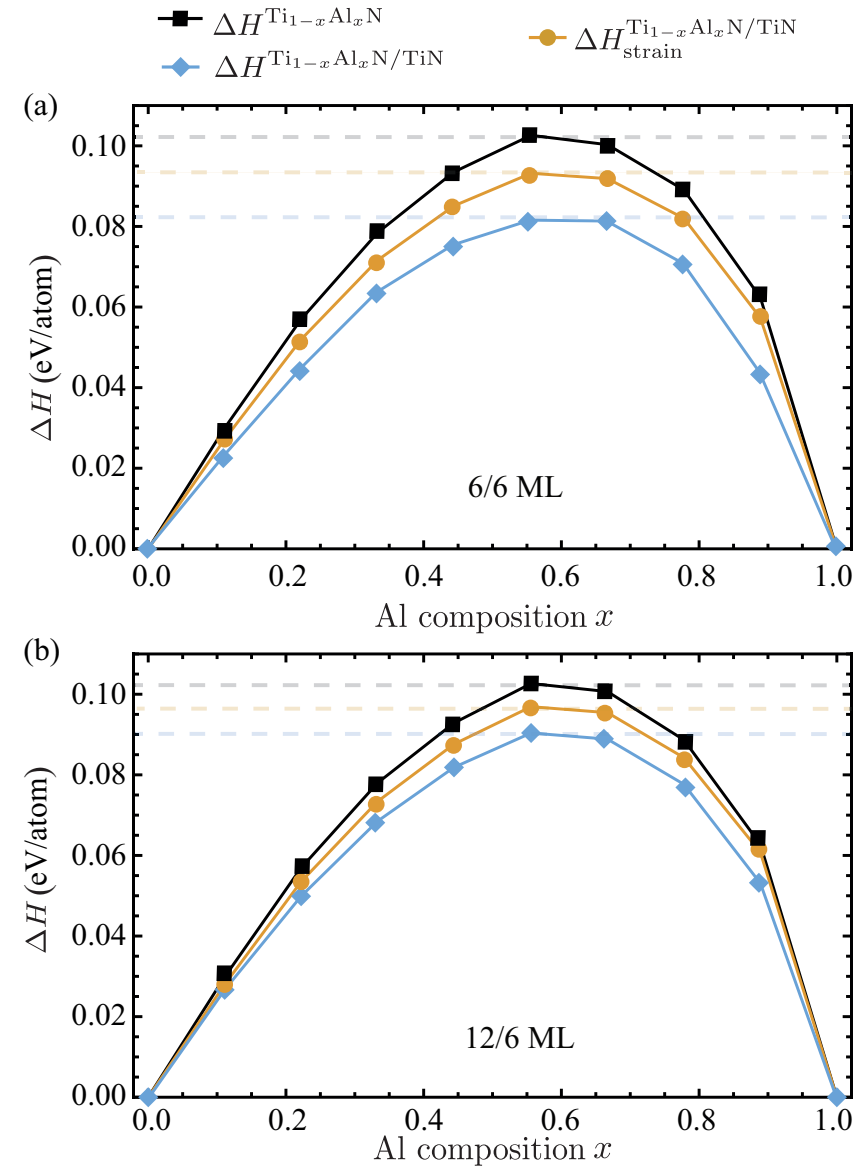

FIG. 1. The mixing enthalpy of bulk $\mathrm{Ti}_{1-x} \mathrm{Al}_{x} \mathrm{~N}$ (ab initio), the mixing enthalpy with the coherency strain effect, and the mixing enthalpy ( $a b$ initio) of $\mathrm{Ti}_{1-x} \mathrm{Al}_{x} \mathrm{~N} / \mathrm{TiN}$ multilayer (ML). (a) 6/6 ML and (b) 12/6 ML. The dashed lines show the maximum of the mixing enthalpy values for the bulk and the different ML case.

Fig. 2. It provides evidence of the in-plane strain effects on the mixing enthalpy.

Figure 2 shows the lattice parameter differences between bulk $\mathrm{Ti}_{1-x} \mathrm{Al}_{x} \mathrm{~N}$ at arbitrary $x$ and the relaxed $\mathrm{B} 1-\mathrm{AlN}$ and $\mathrm{B} 1-\mathrm{TiN}$ lattices (dashed lines). This strain is heavily reduced in the multilayers as the lattice parameter of the B1-AlN/TiN

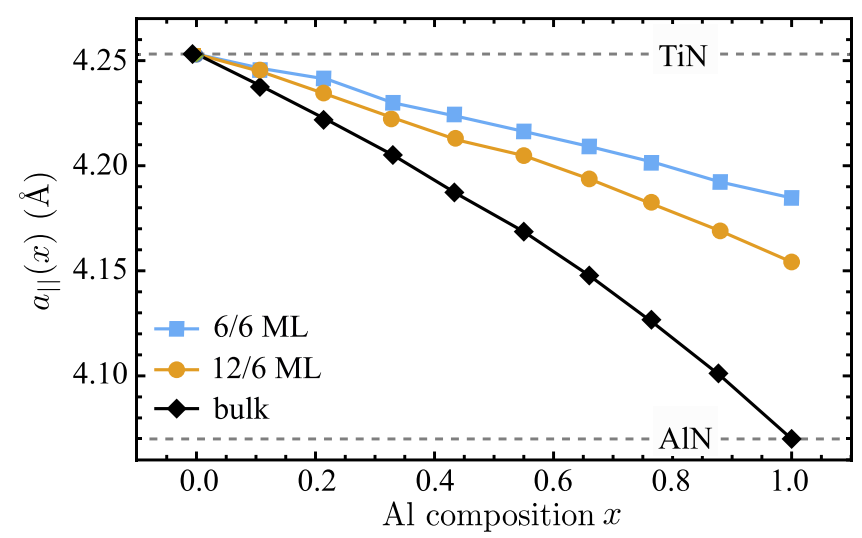

FIG. 2. In-plane lattice parameters of multilayers $6 / 6$ and $12 / 6$ : $a_{\mathrm{Ti}_{1-\mathrm{x}} \mathrm{Al}_{\mathrm{x}} \mathrm{N} / \mathrm{TiN}}$ and bulk: $a_{\mathrm{Ti}_{1-\mathrm{x}} \mathrm{Al}_{\mathrm{x}} \mathrm{N}}$. 

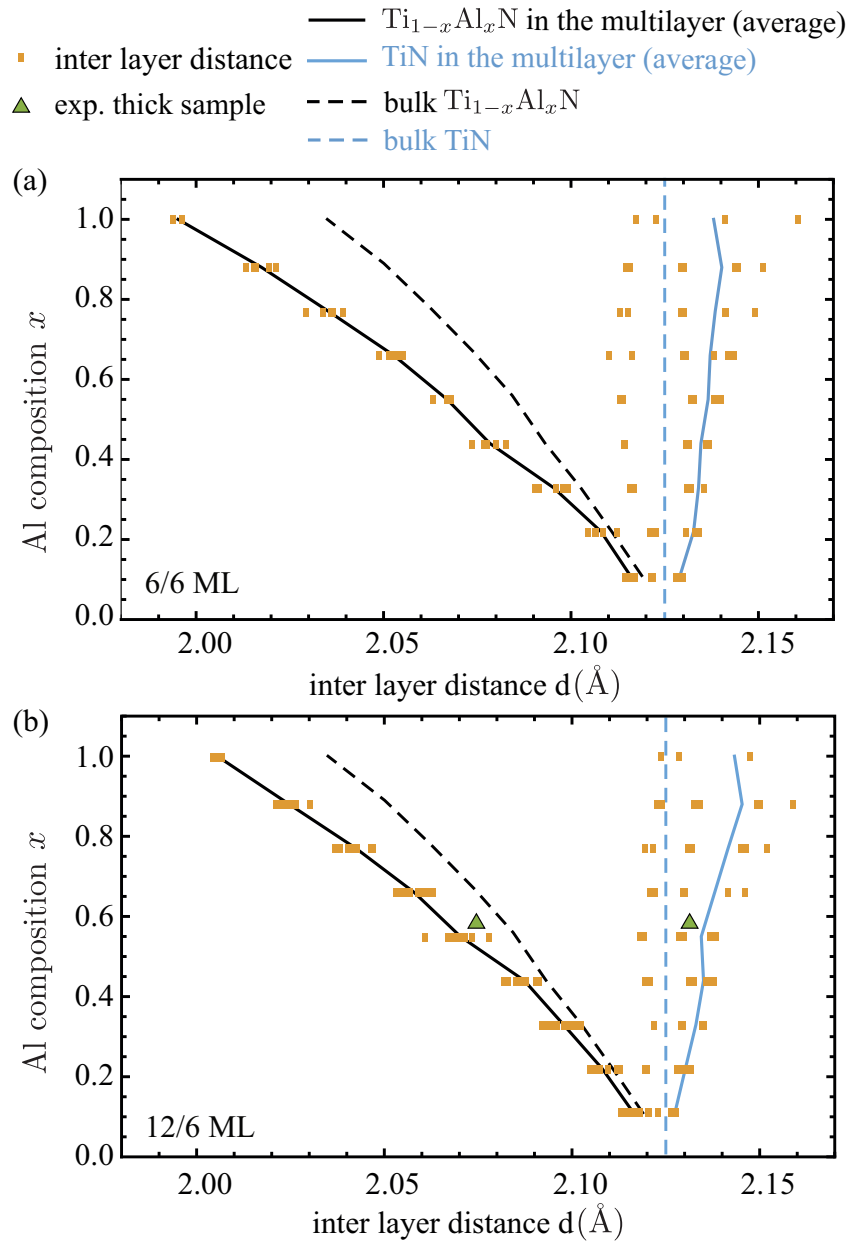

FIG. 3. The calculated averaged interlayer distances $d$ using the fully relaxed structures of both MLs. (a) 6/6 ML and (b) 12/6 ML. The solid lines show the average of the interlayer distance for $\mathrm{Ti}_{1-x} \mathrm{Al}_{x} \mathrm{~N}$ and $\mathrm{TiN}$ in the MLs, while the dashed lines show the bulk cases.

multilayer is significantly larger than B1-AlN. One also sees that this in-plane lattice mismatch is larger in the $12 / 6 \mathrm{ML}$ than in the $6 / 6 \mathrm{ML}$ [higher gradient of $a_{\|}(x)$ ], which correlates with the smaller stabilization effect observed for 12/6 ML in Fig. 1.

Figure 3 shows the calculated averaged interlayer distances $d$ using the fully relaxed structures of the MLs. It is seen that at each composition $x$ one observes mainly three branches of points. Inside the $\mathrm{Ti}_{1-x} \mathrm{Al}_{x} \mathrm{~N}$ slab, the interlayer distance scatter is small while in the TiN slab one finds two branches. The solid lines show the average of the interlayer distance for $\mathrm{Ti}_{1-x} \mathrm{Al}_{x} \mathrm{~N}$ and $\mathrm{TiN}$ in the MLs, while the dashed lines plot $d$ in the bulk cases. It is clear that in both multilayers, the $\mathrm{Ti}_{1-x} \mathrm{Al}_{x} \mathrm{~N}$ slab shrinks along the [001] direction with respect to the bulk while the TiN layer expands. A multilayer sample was grown using an industrial reactive cathodic arc evaporation system from Sulzer/Metaplas (MZR-323); see more experimental details in Ref. [27]. The layer distances of the sample with $x=0.58,6.2 \mu \mathrm{m}$ thickness, and a bilayer period of $37 \mathrm{~nm}$ were obtained by measuring the plane spacing in the direction normal to the surface for the 422 lattice planes. The plane spacings of $\mathrm{Ti}_{0.42} \mathrm{Al}_{0.58} \mathrm{~N}$ and TiN (normal to
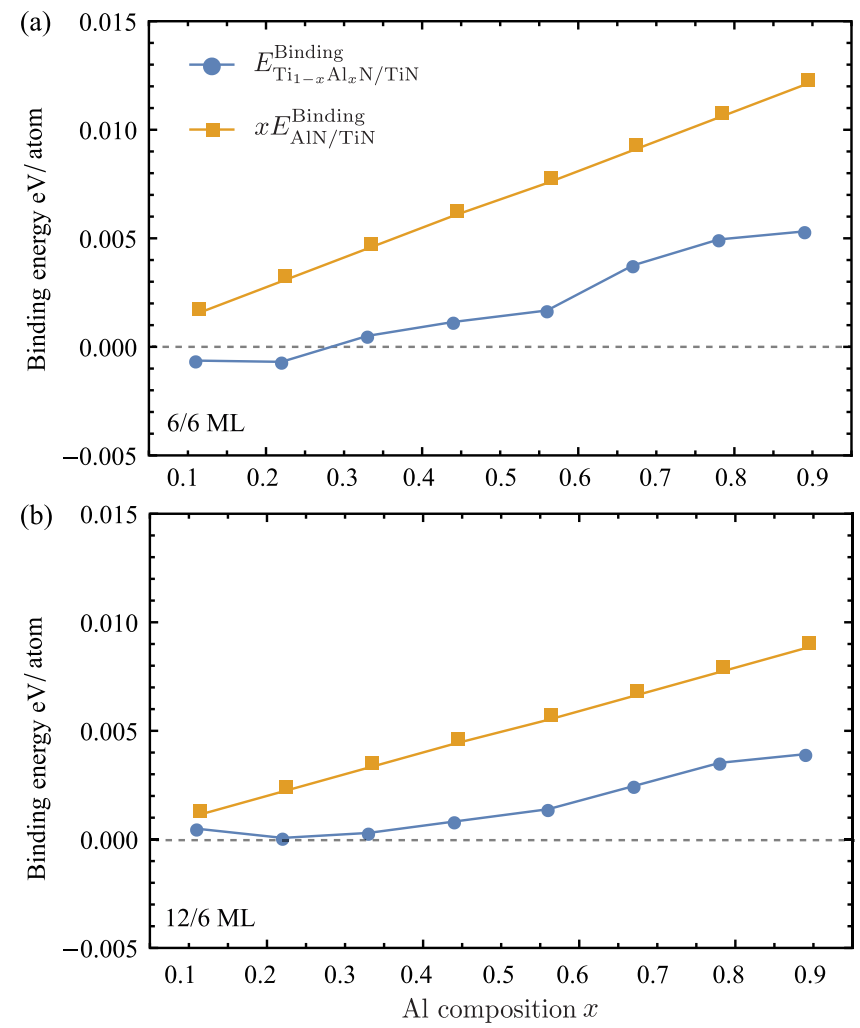

FIG. 4. Comparison of the two chemical effects (normalized binding energy), the one from $\mathrm{Ti}_{1-x} \mathrm{Al}_{x} \mathrm{~N} / \mathrm{TiN}$ and the other form AlN/TiN in the mixing enthalpy of the $\mathrm{Ti}_{1-x} \mathrm{Al}_{x} \mathrm{~N} / \mathrm{TiN}$ multilayer. (a) shows the $6 / 6 \mathrm{ML}$ while (b) displays the $12 / 6 \mathrm{ML}$.

surface) are 4.15 and $4.263 \AA$, respectively. The corresponding interlayer distances are also plotted in Fig. 3(b) as green triangles. Focusing only on the $\mathrm{Ti}_{1-x} \mathrm{Al}_{x} \mathrm{~N}$ slab, one sees that for any $x$ it shrinks less in the $12 / 6 \mathrm{ML}$ than in the $6 / 6$. This is in accord with that observed in Fig. 2, and therefore the same stabilization argument can be used. The fact that these two figures coherently express the strain effect on the mixing enthalpy of the multilayers suggests that the structural misfit can be used as a partial measure of the relative energetics of the multilayer.

To quantify the full effect of strain on the mixing enthalpy in Eq. (1), one needs to include both the coherent in-plane lattice parameters and the modified lattice structure along the (001) growth direction. One can assume that an experimental structure analysis of the thick multilayers that are grown in practice would result in three peaks for the interlayer distances $d$ along [001]: (i) bulk $\mathrm{Ti}_{1-x} \mathrm{Al}_{x} \mathrm{~N}$, (ii) bulk TiN, and (iii) some averaged interfacial interlayer distances. The presence (or amplitude) of the third peak depends on the amount of material with that interfacial structure. Having all of this crystallographic information, one can write the coherency strain part of the mixing enthalpy $\Delta H^{\mathrm{Ti}_{1-\mathrm{x}} \mathrm{Al}_{\mathrm{x}} \mathrm{N} / \mathrm{TiN}}$ as

$$
\begin{aligned}
& \Delta H_{\text {strain }}^{\mathrm{Ti}_{1-x} \mathrm{Al}_{\mathrm{x}} \mathrm{N} / \mathrm{TiN}} \\
& \quad=\frac{1}{N}\left(\mathcal{E}_{\ell_{1} / \ell_{2}}^{\mathrm{Ti}_{1-x} \mathrm{Al}_{\mathrm{x}} \mathrm{N} / \mathrm{TiN}}(x)-(1-x) \mathcal{E}_{\ell_{1}+\ell_{2}}^{\mathrm{TiN}}-x \mathcal{E}_{\ell_{1} / \ell_{2}}^{\mathrm{AlN} / \mathrm{TiN}}\right),
\end{aligned}
$$


(a)
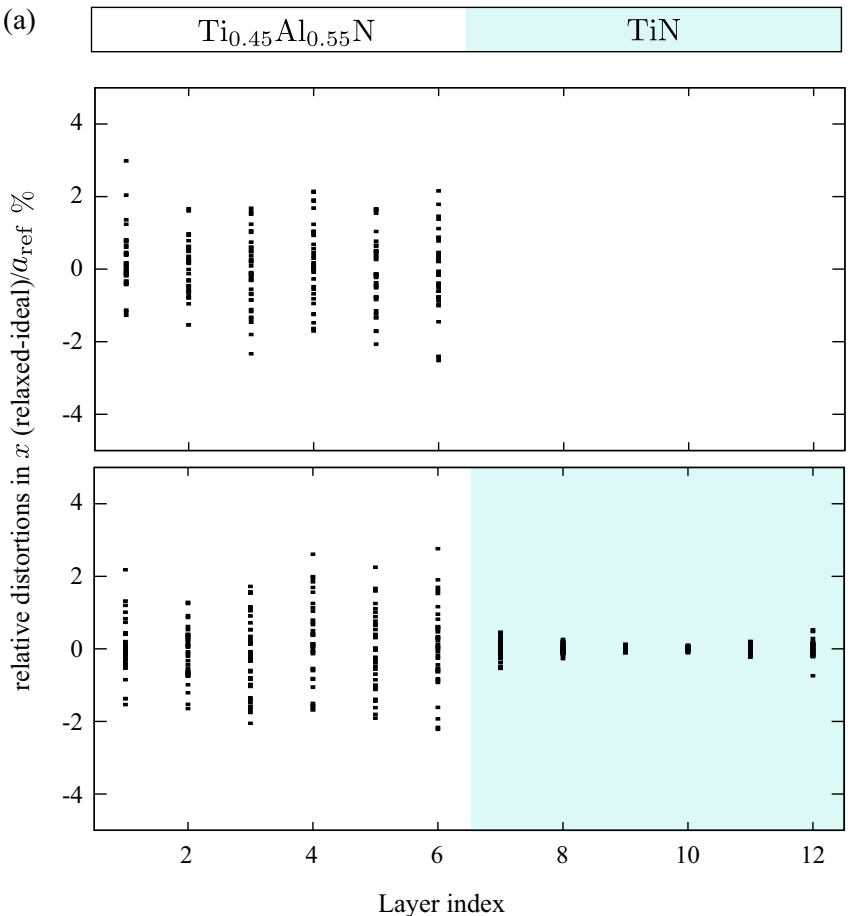

(c)

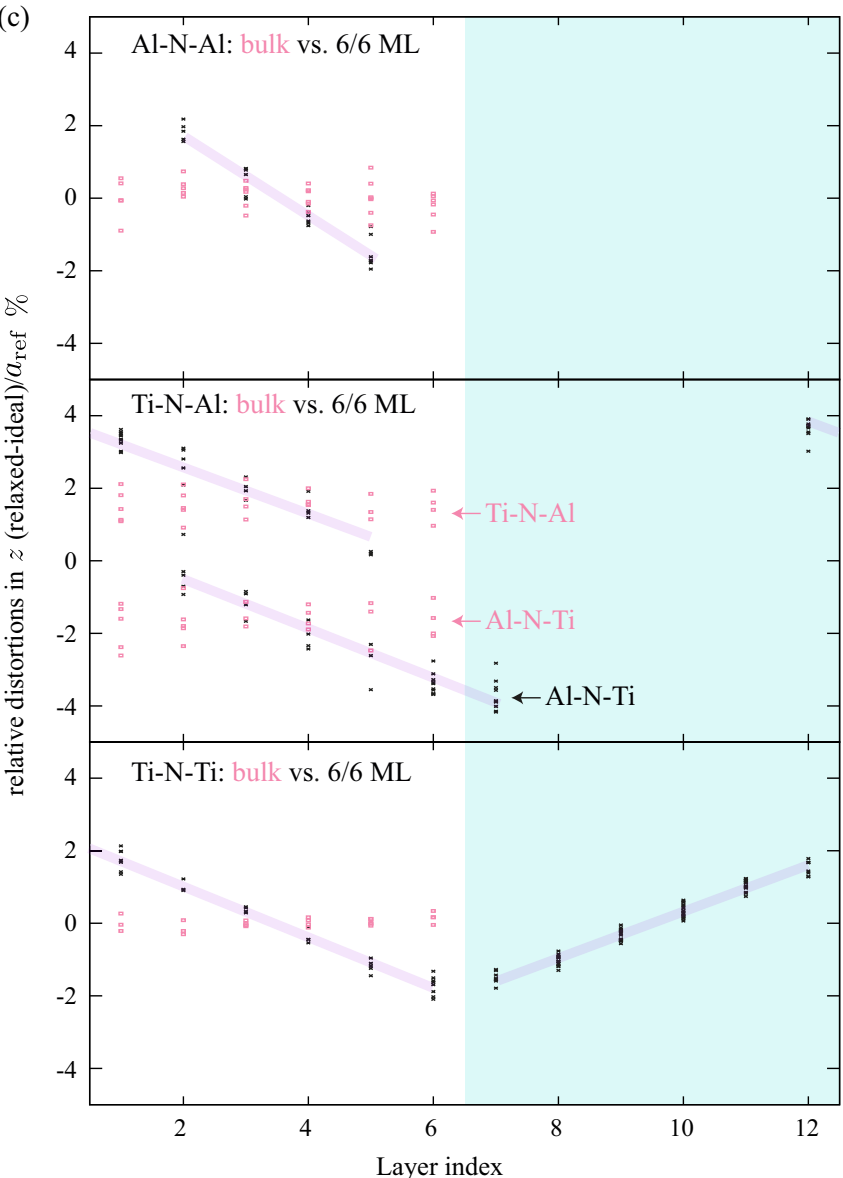

(b)
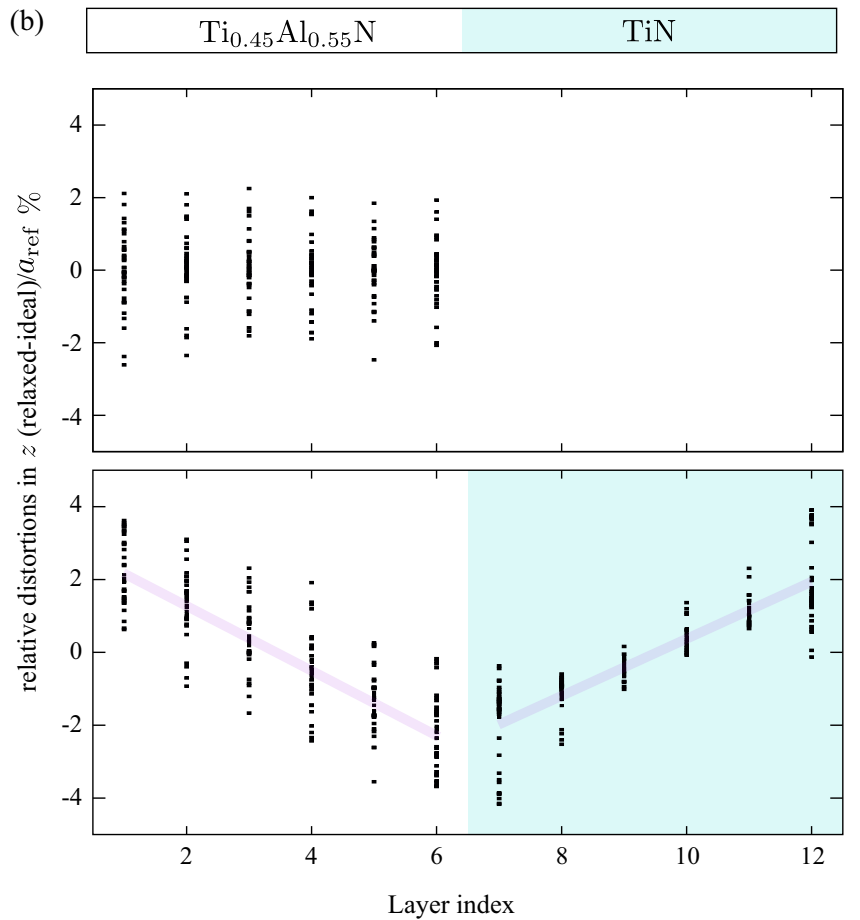

(d)

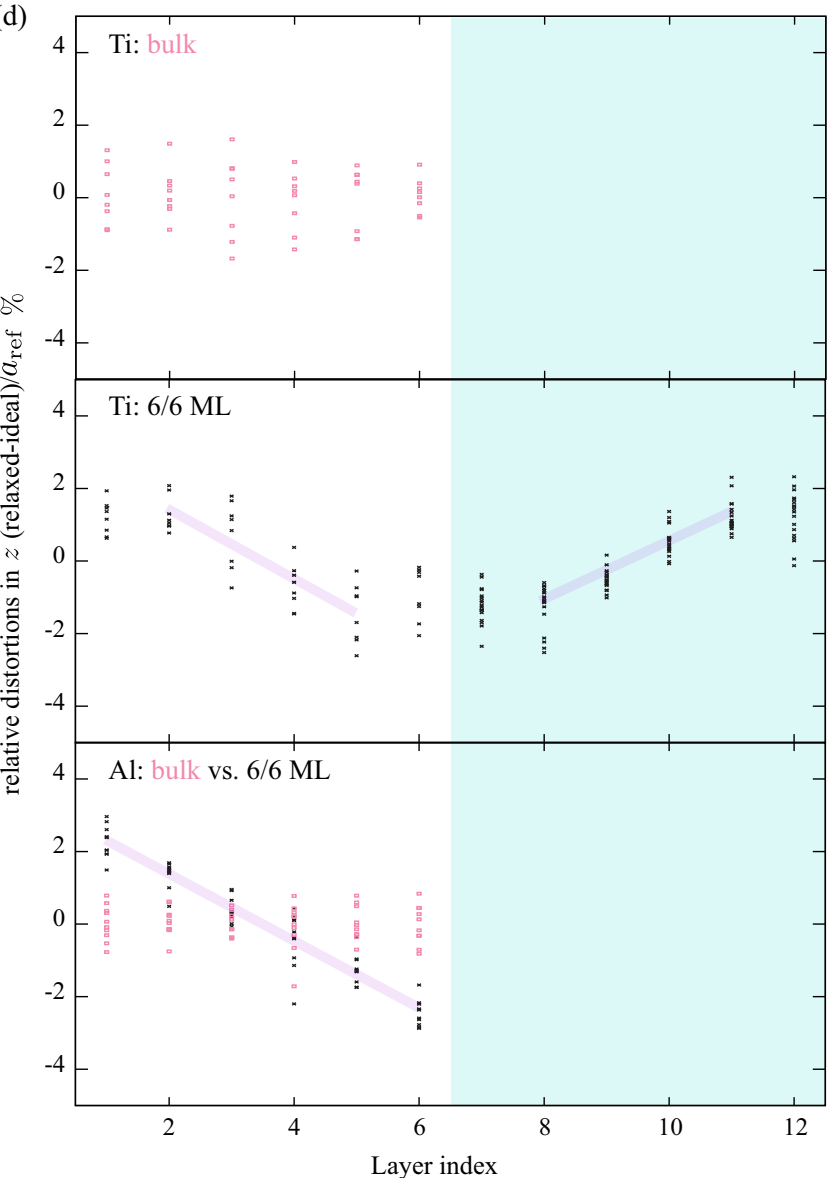

FIG. 5. The atomic relaxations with respect to the ideal positions in each layer for $x=0.55$ of bulk $\mathrm{Ti}_{1-x} \mathrm{Al}_{x} \mathrm{~N}$ and $6 / 6 \mathrm{ML}$ (a) in the $x$ direction and (b) in the $z$ direction. (c) The relaxations of the $\mathrm{N}$ atoms with different types of neighbors (Al-N-Al, Ti-N-Al, and Ti-N-Ti) along the $z$ direction. (d) The relaxations of the Ti and Al atoms along the $z$ direction. See the text for more details. 
with the definition

$$
\begin{aligned}
& \mathcal{E}_{\ell_{1} / \ell_{2}}^{\mathrm{Ti}_{1-x} \mathrm{Al}_{\mathrm{x}} \mathrm{N} / \mathrm{TiN}}(x) \\
& =\frac{\ell_{1}}{\ell_{2}} E_{\ell_{1}+\ell_{2}}^{\mathrm{Ti}_{1-x} \mathrm{Al}_{\mathrm{x}} \mathrm{N}}\left(x, a_{\|}^{\mathrm{Ti}_{1-\mathrm{x}} \mathrm{Al}_{\mathrm{x}} \mathrm{N} / \mathrm{TiN}},\left\langle c^{\mathrm{Ti}_{1-\mathrm{x}} \mathrm{Al}_{\mathrm{x}} \mathrm{N}}\right\rangle_{\mathrm{Ti}_{1-\mathrm{x}} \mathrm{Al} \mathrm{x} / \mathrm{TiN}}\right)
\end{aligned}
$$

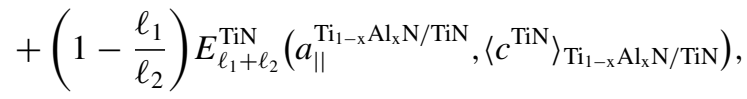

$$
\begin{aligned}
& \mathcal{E}_{\ell_{1} / \ell_{2}}^{\mathrm{AlN} / \mathrm{TiN}}(x) \\
& =\frac{\ell_{1}}{\ell_{2}} E_{\ell_{1}+\ell_{2}}^{\mathrm{AlN}}\left(x, a_{\|}^{\mathrm{AlN} / \mathrm{TiN}},\left\langle c^{\mathrm{AlN}}\right\rangle_{\mathrm{AlN} / \mathrm{TiN}}\right) \\
& +\left(1-\frac{\ell_{1}}{\ell_{2}}\right) E_{\ell_{1}+\ell_{2}}^{\mathrm{TiN}}\left(a_{\|}^{\mathrm{AlN} / \mathrm{TiN}},\left\langle c^{\mathrm{TiN}}\right\rangle_{\mathrm{AlN} / \mathrm{TiN}}\right) .
\end{aligned}
$$

Here $\mathcal{E}$ is the energy of a multilayer with a periodicity of $\ell_{1} / \ell_{2}$ when using the optimized averaged lattice parameters with no chemical interaction through the interface. $E$ stands for the total energy, $a_{\|}^{\mathrm{Ti}_{1-\mathrm{x}} \mathrm{Al} \mathrm{x} / \mathrm{TiN}}$ and $a_{\|}^{\mathrm{AlN} / \mathrm{TiN}}$ are the coherent inplane lattice parameters of the $\mathrm{Ti}_{1-\mathrm{x}} \mathrm{Al}_{\mathrm{X}} \mathrm{N} / \mathrm{TiN}$ and $\mathrm{AlN} / \mathrm{TiN}$ multilayers, and $\left\langle c^{\mathrm{Ti}_{1-x} \mathrm{Al}_{\mathrm{x}} \mathrm{N}}\right\rangle_{\mathrm{Ti}_{1-x} \mathrm{Al}} \mathrm{A} \mathrm{N} / \mathrm{TiN},\left\langle c^{\mathrm{TiN}}\right\rangle_{\mathrm{Ti}_{1-x} \mathrm{Al}_{\mathrm{x}} \mathrm{N} / \mathrm{TiN}}$, $\left\langle c^{\mathrm{AlN}}\right\rangle_{\mathrm{AlN} / \mathrm{TiN}}$, and $\left\langle c^{\mathrm{TiN}}\right\rangle_{\mathrm{AlN} / \mathrm{TiN}}$ denote the averaged lattice parameters corresponding to the peaks (1) and (2) in the derived/observed interlayer distances.

Using the averaged interlayer distances (solid lines) from Fig. 3 in Eqs. (2) and (3), one defines the effect of strain on the mixing enthalpy. The calculated $\Delta H_{\text {strain }}^{\mathrm{Ti}_{1-x} \mathrm{Al}_{\mathrm{x}} \mathrm{N} / \mathrm{TiN}}$ values are shown in Fig. 1. It is seen that the strain effect due to the presence of the coherent interfaces with TiN stabilizes the alloy, however it does not account for the full decrease of the mixing enthalpy. The rest of the stabilization effect is defined as the local interfacial or chemical contribution. This chemical contribution is even more significant than the coherency strain effect. By subtracting the strain term [Eq. (3)] from each of the energy terms in Eq. (1), one derives the chemical contribution to $\Delta H^{\mathrm{Ti}_{1-\mathrm{x}} \mathrm{Al}_{\mathrm{x}} \mathrm{N} / \mathrm{TiN}}$ including both interfaces: the $\mathrm{Ti}_{1-x} \mathrm{Al}_{x} \mathrm{~N} / \mathrm{TiN}(001)$ and the $\mathrm{AlN} / \mathrm{TiN}(001)$. These binding energies Eq. (4) are shown in Fig. 4,

$$
\begin{aligned}
E_{\mathrm{Ti}_{1-\mathrm{x}} \mathrm{Al}_{\mathrm{x}} \mathrm{N} / \mathrm{TiN}}^{\mathrm{binding}}(x) & =E_{\ell_{1}+\ell_{2}}^{\mathrm{Ti}_{1-\mathrm{x}} \mathrm{Al}_{\mathrm{x}} \mathrm{N} / \mathrm{TiN}}(x)-\mathcal{E}_{\ell_{1} / \ell_{2}}^{\mathrm{Ti}_{1_{-}} \mathrm{Al}_{\mathrm{x}} \mathrm{N} / \mathrm{TiN}}(x), \\
E_{\mathrm{AlN} / \mathrm{TiN}}^{\mathrm{binding}}(x) & =E_{\ell_{1}+\ell_{2}}^{\mathrm{AlN} / \mathrm{TiN}}(x)-\mathcal{E}_{\ell_{1} / \ell_{2}}^{\mathrm{AlN} / \mathrm{TiN}}(x) .
\end{aligned}
$$

The overall chemical (interfacial) stabilization can be obtained by subtracting the latter one from the former. One should note that the binding energy in $\mathrm{Ti}_{1-x} \mathrm{Al}_{x} \mathrm{~N} / \mathrm{TiN}(001)$ is mostly positive, which says that it costs extra energy to build the interface. However, this energy is less than what one obtains for the AlN/TiN(001) interface. Therefore, the decomposition of $\mathrm{Ti}_{1-x} \mathrm{Al}_{x} \mathrm{~N}$ interfaced coherently to $\mathrm{TiN}$ is also hindered by the interfacial chemistry.

The nonvanishing multilayer binding energy in $\mathrm{Ti}_{1-x} \mathrm{Al}_{x} \mathrm{~N} /$ TiN(001) (see Fig. 4) indicates that the atomic coordinates, especially at the interfaces, should show significant deviations from their ideal lattice positions, the so-called atomic relaxations.

The layer-resolved atomic relaxations (scaled, coherent B1 lattice) are shown in Fig. 5. The ideal structures were considered at the volume of the fully relaxed structure for both the bulk and the ML case. The figure shows the
TABLE I. The fitted slopes values (\%) of the straight lines and the corresponding shifts of the layers in the ML slabs ( $\AA$ ) (in parentheses).

\begin{tabular}{lcc}
\hline \hline & $\mathrm{Ti}_{0.45} \mathrm{Al}_{0.55} \mathrm{~N}$ & $\mathrm{TiN}$ \\
\hline Fig. 5(b) & $-0.89(-0.019)$ & $0.78(0.016)$ \\
Fig. 5(c) & & \\
Al-N-Al & $-1.10(-0.023)$ & \\
Ti-N-Al & $-0.64(-0.013)$ & \\
Al-N-Ti & $-0.68(-0.014)$ & $0.64(0.013)$ \\
Ti-N-Ti & $-0.70(-0.015)$ & $0.85(0.018)$ \\
Fig. 5(d) & & \\
Ti & $-0.96(-0.020)$ & \\
Al & $-0.92(-0.019)$ & \\
\hline \hline
\end{tabular}

relaxations only for $x=0.55$, and the values are measured in percentage of the lattice parameter of the bulk $\operatorname{Ti}_{0.45} \mathrm{Al}_{0.55} \mathrm{~N}$, $a_{\text {ref }}=a_{\mathrm{Ti}_{0.45} \mathrm{Al}_{0.55} \mathrm{~N}}=4.16 \AA$. The horizontal axis is the layer number. Figure 5(a) gives a comparison of the relaxations in the $x$ direction (perpendicular to the growth direction). A very similar dispersion of the relaxations has been obtained in the $y$ direction (which is not shown here). One sees that the relaxations in the $\mathrm{Ti}_{0.45} \mathrm{Al}_{0.55} \mathrm{~N}$ slab [bottom part of Fig. 5(a)] are very similar to the bulk case [upper part of Fig. 5(a)], while in the TiN part just the interfacial layers show some distortions, i.e., $\pm 1 \%$ wide scattering.

Along the growth direction, a strong difference between the relaxations in ML and bulk is seen [see Fig. 5(b)]. Although the width of the scatter within each monolayer of $\mathrm{Ti}_{0.45} \mathrm{Al}_{0.55} \mathrm{~N}$ agrees well between ML and bulk, a systematic shift of the layers as a whole is observed. The shifts are shown by the straight lines fitted to the relaxations of the individual atoms. The fitted slopes and the corresponding shifts of the layers in the ML slab are summarized in Table I. It is already known from Fig. 3 that the $\mathrm{Ti}_{0.45} \mathrm{Al}_{0.55} \mathrm{~N}$ slab shrinks while the TiN one expands. This observation is represented by the distinct slopes of the lines. Using the reference value $a_{\text {ref }}$, one calculates the constant average shifts; see Table I. For example, in the $\mathrm{Ti}_{0.45} \mathrm{Al}_{0.55} \mathrm{~N}$ slab one obtains $-0.019 \AA$, which agrees with the value plotted in Fig. 3. In Fig. 5(c), the relaxations of the $\mathrm{N}$ atoms with different types of neighbors (Al-N-Al, Ti-N-Al, and Ti-N-Ti) along the growth direction are shown. It is seen that the plane with the $\mathrm{N}$ atoms surrounded (from above and below) only by $\mathrm{Al}$ atoms has the largest shift, while the other ones, even in the TiN slab, show the same shift around $0.014 \AA$. Figure 5(d) compares the relaxations of the $\mathrm{Al}$ and $\mathrm{Ti}$ atoms. One sees that the $\mathrm{Ti}$ atoms in the TiN slab scatter wider in the growth direction than in $x$; see Fig. 5(a). However, the most striking result is the average relaxation of the layers of $\mathrm{Ti}$ atoms. In the interfacial layers (layer numbers 1,12 or 6,7), the average relaxation of the $\mathrm{Ti}$ atoms breaks the common trend, i.e., they do not sit on the fitted straight lines. The Ti atoms in layer 6 in the multilayer have an increased amount of $\mathrm{Ti}$ first neighbors from layer 7 (TiN slab), which results in a stronger binding between the two layers via the Ti- $d$ orbitals. According to the fitted straight lines, the Ti atoms in layer 6 should shift down while in layer 7 they should relax upwards. However, the increased binding results in an increased interlayer distance between layers 5 


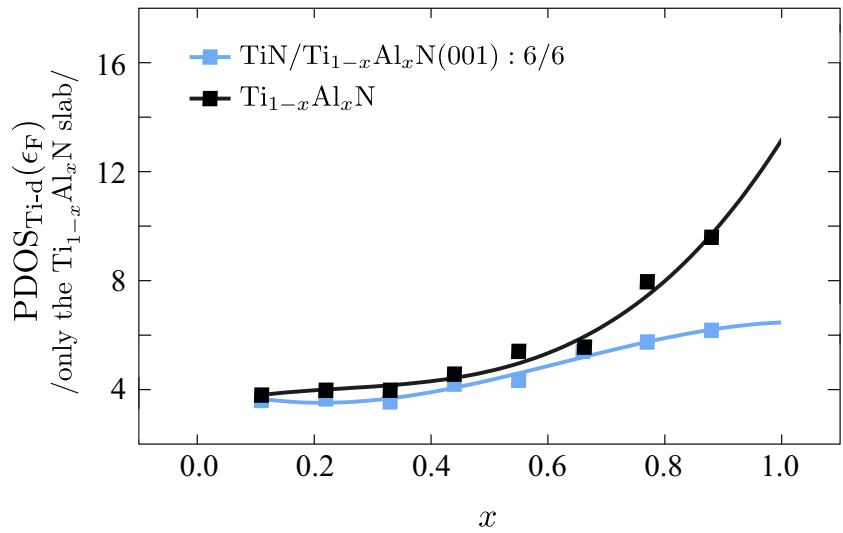

FIG. 6. Bulk and the $6 / 6$ multilayer $d$-orbital partial density of states (PDOS) at the Fermi energy $\left(\epsilon_{\mathrm{F}}\right)$ of the Ti atoms from only the $\mathrm{Ti}_{1-x} \mathrm{Al}_{x} \mathrm{~N}$ slab.

and $6\left(\mathrm{Ti}_{0.45} \mathrm{Al}_{0.55} \mathrm{~N}\right.$ slab) while it becomes smaller between layers 7 and 8 (TiN slab). These local interfacial relaxations underline the fact that the interactions between the interfacial atoms along the growth directions differ from those in bulk $\mathrm{Ti}_{1-x} \mathrm{Al}_{x} \mathrm{~N}$ alloy. In multilayers one should use layer-resolved effective interactions to express the configurational energetics, and one expects a significant contribution from the on-site interactions; see Ref. [18].

Let us now discuss the electronic structure of the studied system. Figure 6 compares the Ti-site $d$-orbital partial density of states (PDOS) at the Fermi energy $\left(\epsilon_{\mathrm{F}}\right)$ of the $\mathrm{Ti}_{1-x} \mathrm{Al}_{x} \mathrm{~N}$ slabs in the 6/6 ML with those in the bulk. The lower PDOS values in the ML mean increased Ti-Ti hybridization, which is explained as the stabilization effect in the bulk [12]. The figure shows that with increasing $\mathrm{Al}$ content, this electronic stabilization effect in the ML increases more compared to the bulk, which correlates well with the observed increased multilayer binding energy displayed in Fig. 4. Since the increase of Ti-site projected DOS at $\epsilon_{\mathrm{F}}$ with increasing $\mathrm{Al}$ content indicates the increased tendency toward decomposition [12] in the bulk, we underline that this effect is clearly suppressed in the ML by means of more $d-d$ hybridization.

\section{CONCLUSIONS}

In this study, we investigated the mixing thermodynamics of cubic (B1) $\mathrm{Ti}_{1-x} \mathrm{Al}_{x} \mathrm{~N} / \mathrm{TiN}(001)$ multilayers, and we showed that the mixing enthalpy is suppressed compared with bulk $\mathrm{Ti}_{1-x} \mathrm{Al}_{x} \mathrm{~N}$ by the interfacial effects. That is, the coherent interface with TiN was shown to stabilize $\mathrm{Ti}_{1-x} \mathrm{Al}_{x} \mathrm{~N}$. We predict the largest effect around the composition where the mixing enthalpy of bulk $\mathrm{Ti}_{1-x} \mathrm{Al}_{x} \mathrm{~N}$ has its maximum. The decrease of the mixing enthalpy in the multilayers was then split into a strain and an interfacial chemical contribution, and both effects are equally important. The in-plane lattice mismatch between $\mathrm{Ti}_{1-x} \mathrm{Al}_{x} \mathrm{~N} / \mathrm{TiN}(001)$ and $\mathrm{AlN} / \mathrm{TiN}(001)$ was shown to correlate with the stabilization. The full strain contribution to the suppression was discussed on the basis of the structural properties of the multilayers. The fact that the lattice parameter and interlayer distances coherently expressed the stabilization effect of the structural misfit was suggested as a good partial measure of the relative energetics of the multilayers. We showed that the chemical effects result in large local atomic relaxations, especially for the $\mathrm{Ti}$ atoms on both sides of the interface. By calculating the electronic structure for the multilayer, we observe that the increase of Ti-site projected DOS at $\epsilon_{\mathrm{F}}$ with increasing $\mathrm{Al}$ content, known as the electronic origin of a strong tendency toward the decomposition in the bulk $\mathrm{Ti}_{1-x} \mathrm{Al}_{x} \mathrm{~N}$, is clearly suppressed in the multilayer.

\section{ACKNOWLEDGMENTS}

The authors would like to gratefully acknowledge the support from the Swedish Foundation for Strategic Research (SSF) project SRL Grant No. 10-0026 and Multiscale computational-design of novel hard nanostructure coatings. The calculations were carried out through the Swedish National Infrastructure for Computing (SNIC), and they were performed at the Swedish National Supercomputer Center (NSC) for high performance computing. F.W. acknowledges funding received through Erasmus Mundus Joint European Doctoral Programme DocMASE. I.A.A. wishes to acknowledge the Swedish Research Council (VR) Grant No. 201504391, the Grant of Ministry of Education and Science of the Russian Federation (Grant No. 14.Y26.31.0005), and Tomsk State University Academic D. I. Mendeleev Fund Program (Project No. 8.1.18.2015). M.O. acknowledges the Swedish Research Council (VR) Grant No. 621-2012-4401. The support from Swedish Research Council (VR) (Project No. 2014-4750), LiLi-NFM, and the Swedish Government Strategic Research Area Grant in Materials Science to the AFM research environment at LiU are acknowledged.
[1] M. Shinn, L. Hultman, and S. A. Barnett, J. Mater. Res. 7, 901 (1992).

[2] U. Helmersson, S. Todorova, S. A. Barnett, J. E. Sundgren, L. C. Markert, and J. E. Greene, J. Appl. Phys. 62, 481 (1987).

[3] L. Hultman, C. Engström, and M. Odén, Surf. Coat. Technol. 133-134, 227 (2000).

[4] M.-L. Wu, W.-D. Qian, Y.-W. Chung, Y.-Y. Wang, M.-S. Wong, and W. D. Sproul, Thin Solid Films 308-309, 113 (1997).

[5] N. Ghafoor, H. Lind, F. Tasnádi, I. A. Abrikosov, and M. Odén, APL Mater. 2, 046106 (2014).
[6] J. S. Koehler, Phys. Rev. B 2, 547 (1970).

[7] R. G. Hoagland, T. E. Mitchell, J. P. Hirth, and H. Kung, Philos. Mag. A 82, 643 (2002).

[8] I. N. Mastorakos, H. M. Zbib, and D. F. Bahr, Appl. Phys. Lett. 94, 173114 (2009).

[9] V. Ozolinšs, C. Wolverton, and A. Zunger, Phys. Rev. B 57, 4816 (1998).

[10] A. Knutsson, M. P. Johansson, L. Karlsson, and M. Odén, J. Appl. Phys. 108, 044312 (2010).

[11] A. Knutsson, M. P. Johansson, L. Karlsson, and M. Odén, Surf. Coat. Technol. 205, 4005 (2011). 
[12] B. Alling, A. V. Ruban, A. Karimi, O. E. Peil, S. I. Simak, L. Hultman, and I. A. Abrikosov, Phys. Rev. B 75, 045123 (2007).

[13] F. Tasnádi, F. Wang, M. Odén, and I. A. Abrikosov, Comput. Mater. Sci. 103, 194 (2015).

[14] A. van De Walle and D. E. Ellis, Phys. Rev. Lett. 98, 266101 (2007).

[15] A. Zunger, S. H. Wei, L. G. Ferreira, and J. E. Bernard, Phys. Rev. Lett. 65, 353 (1990).

[16] N. Shulumba, O. Hellman, Z. Raza, J. Barrirero, B. Alling, F. Mücklich, I. A. Abrikosov, and M. Odén, arXiv:1503.02459.

[17] I. A. Abrikosov, S. I. Simak, B. Johansson, A. V. Ruban, and H. L. Skriver, Phys. Rev. B 56, 9319 (1997).

[18] A. V. Ruban and I. A. Abrikosov, Rep. Prog. Phys. 71, 046501 (2008).
[19] X. Chu and S. Barnett, J. Appl. Phys. 77, 4403 (1995).

[20] P. E. Blöchl, Phys. Rev. B 50, 17953 (1994).

[21] G. Kresse and J. Hafner, Phys. Rev. B 47, 558 (1993).

[22] G. Kresse and J. Hafner, Phys. Rev. B 49, 14251 (1994).

[23] G. Kresse and J. Furthmüller, Phys. Rev. B 54, 11169 (1996).

[24] J. Perdew, J. Chevary, S. Vosko, K. Jackson, M. Pederson, D. Singh, and C. Fiolhais, Phys. Rev. B 48, 4978 (1993).

[25] J. P. Perdew, K. Burke, and M. Ernzerhof, Phys. Rev. Lett. 77, 3865 (1996).

[26] J. D. Pack and H. J. Monkhorst, Phys. Rev. B 16, 1748 (1977).

[27] A. Knutsson, I. C. Schramm, K. Asp Grönhagen, F. Mücklich, and M. Odén, J. Appl. Phys. 113, 114305 (2013). 